\title{
Organic carbon burial efficiency in a subtropical hydroelectric reservoir
}

\author{
Raquel Mendonça ${ }^{1,2}$, Sarian Kosten ${ }^{3}$, Sebastian Sobek ${ }^{2}$, Simone Jaqueline Cardoso ${ }^{1}$, \\ Marcos Paulo Figueiredo-Barros ${ }^{4}$, Carlos Henrique Duque Estrada ${ }^{1}$, and Fábio Roland ${ }^{1}$ \\ ${ }^{1}$ Laboratory of Aquatic Ecology, Department of Biology, Federal University of Juiz de Fora, Juiz de Fora, Brazil \\ ${ }^{2}$ Department of Ecology and Genetics, Limnology, Uppsala University, Uppsala, Sweden \\ ${ }^{3}$ Aquatic Ecology \& Environmental Biology, Institute of Water and Wetland Research, Radboud University, \\ Nijmegen, the Netherlands \\ ${ }^{4}$ Laboratório de Limnologia, Núcleo em Ecologia e Desenvolvimento Sócio Ambiental de Macaé (NUPEM), \\ Universidade Federal do Rio de Janeiro, Macaé, Brazil
}

Correspondence to: Raquel Mendonça (fm.raquel@yahoo.com.br)

Received: 15 October 2015 - Published in Biogeosciences Discuss.: 17 November 2015

Revised: 29 April 2016 - Accepted: 16 May 2016 - Published: 7 June 2016

\begin{abstract}
Hydroelectric reservoirs bury significant amounts of organic carbon (OC) in their sediments. Many reservoirs are characterized by high sedimentation rates, low oxygen concentrations in bottom water and a high share of terrestrially derived OC, and all of these factors have been linked to a high efficiency of OC burial. However, investigations of OC burial efficiency (OCBE, i.e., the ratio between buried and deposited OC) in reservoirs are limited to a few studies, none of which include spatially resolved analyses. In this study we determined the spatial variation in OCBE in a large subtropical reservoir and related it to sediment characteristics. Our results show that the sediment accumulation rate explains up to $92 \%$ of the spatial variability in OCBE, outweighing the effect of other variables, such as OC source and oxygen exposure time. OCBE at the pelagic sites varied from 48 to $86 \%$ (mean $67 \%$ ) and decreased towards the dam. At the margins, OCBE was lower (9-17\%) due to the low sediment accumulation in shallow areas. Our data show that the variability in OCBE both along the rivers-dam and the margin-pelagic axes must be considered in wholereservoir assessments. Combining these results with a spatially resolved assessment of sediment accumulation and OC burial in the studied reservoir, we estimated a spatially resolved mean OC burial efficiency of $57 \%$. Being the first assessment of OCBE with such a high spatial resolution in a reservoir, these results suggest that reservoirs may bury OC more efficiently than natural lakes.
\end{abstract}

\section{Introduction}

The sediments of freshwater systems are important sinks of atmospheric $\mathrm{CO}_{2}$ assimilated through photosynthesis both in the aquatic and in the terrestrial environments (Stallard, 1998). This carbon sink corresponds to the fraction of the organic carbon (OC) that reaches the sediments and escapes mineralization by heterotrophic organisms and (photo)chemical reactions, remaining buried (accumulated). The percentage of the total OC reaching the sediments that is actually buried corresponds to the $\mathrm{OC}$ burial efficiency (OCBE) of a system (Betts and Holland, 1991; Hartnett et al., 1998). OCBE, thus, depends on the processes and factors affecting burial and mineralization. OCBE is closely negatively linked to mineralization: processes favoring mineralization tend to decrease burial and vice versa.

While the mechanisms controlling the carbon fluxes in marine sediments have received considerable attention (see Burdige, 2007 for a review), freshwater sediments have only recently become the focus of study (Sobek et al., 2009; Gudasz et al., 2010, 2012). What is known about freshwater sediments is that OCBE tends to be strongly positively correlated with sedimentation rates, especially of terrestrially derived OC (Sobek et al., 2009; Gudasz et al., 2012). This explains, for instance, why hydroelectric reservoirs tend to be more important sites for OC accumulation, compared to lakes, as reservoirs receive relatively high inputs of fluvial sediments. 
OC burial in reservoirs is about 1 order of magnitude higher than in natural lakes (Mulholland and Elwood, 1982). In spite of the increasing importance of reservoirs as OC burial sites (Mendonça et al., 2012) due to the rising demand for hydroelectricity, assessments of the OC burial efficiency in hydroelectric reservoirs are, to our knowledge, so far limited to two studies on tropical and subtropical systems (Kunz et al., 2011; Sikar et al., 2012) and one in a temperate system (Sobek et al., 2012). None of these assessments are based on highly spatially resolved data.

Organic carbon in hydroelectric reservoirs can originate from several sources (De Junet et al., 2009). First, carbon derived from flooded soil and vegetation may fuel the system's metabolism for long periods, leading to elevated greenhouse gas $(\mathrm{GHG})$ emissions, especially during the initial $\sim 10$ years after damming (Abril et al., 2005; Tremblay et al., 2004; Barros et al., 2011). Second, variable amounts of terrestrial organic matter are continuously flushed into reservoirs through tributary rivers and erosion of the margins. Terrestrial inputs are, thus, important during the entire reservoir lifetime. Finally, the combination of the usually long water residence time, the high transparency due to the settling of suspended sediment and the high nutrient availability favors planktonic primary production in reservoirs (Bayne et al., 1983; Rangel et al., 2012). Terrestrial-derived and aquatic-derived OCs occur in different proportions along reservoirs' length and may be mineralized/buried at different rates (Gudasz et al., 2012; Cardoso et al., 2014). Moreover, the hydrology of hydroelectric reservoirs, marked by the transition between high stream velocities at the river inflow and low velocities near the dam, often leads to remarkable limnological gradients, e.g., water physical and chemical properties, sedimentation and productivity (Thornton, 1990; Armengol et al., 1999).

Reservoir heterogeneity may cause a strong variation in carbon fluxes (Roland et al., 2010; Cardoso et al., 2013). While spatial variation in $\mathrm{CO}_{2}$ emissions from reservoirs' surface to the atmosphere have been described (Roland et al., 2010), the effect of heterogeneity on the sediment-carbon flows is unknown, even though reservoir heterogeneity is clearly reflected in sediment characteristics (De Junet et al., 2009). The main purpose of this study was to determine the OCBE in a subtropical hydroelectric reservoir, and to evaluate the importance of variable factors driving it. OCBE was obtained from direct measurements of OC burial and estimations of OC mineralization rates along the length of a hydropower reservoir in Brazil, including the margins and the pelagic zone. Subsequently, these site-specific measurements were extrapolated to the whole reservoir based on spatially resolved measurements of sediment accumulation and OC burial rates (Mendonça et al., 2014). This approach resulted in the first highly spatially resolved OCBE estimate for a reservoir.

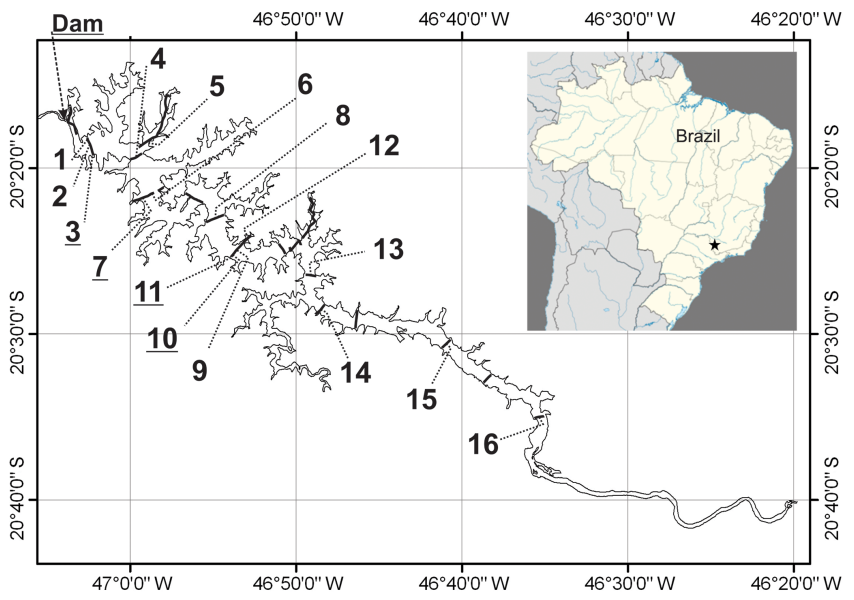

Figure 1. Location of the Mascarenhas de Moraes reservoir (black star in the map of Brazil), its dam and the sampling sites. Underlined numbers correspond to sites located on the margins; other numbers correspond to pelagic sites.

\section{Methods}

\subsection{Reservoir description}

This study was conducted in Mascarenhas de Moraes, a large $\left(272 \mathrm{~km}^{2}\right)$ and deep (maximum depth $60 \mathrm{~m}$ ) hydroelectric reservoir located in southeastern Brazil $\left(20^{\circ} 17^{\prime} 1.52^{\prime \prime} \mathrm{S}\right.$, $47^{\circ} 3^{\prime} 46.53^{\prime \prime} \mathrm{W}$; Fig. 1), in the Cerrado (savannah-type) biome, in a region characterized by subtropical climate. The reservoir was formed by the damming of the Rio Grande in 1957. Its watershed is currently dominated by agriculture (mainly coffee, corn and soybean), with some remnants of original Cerrado forests. Water residence time in the Mascarenhas de Moraes reservoir is relatively short (approximately 51 days, Rangel et al., 2012). Total phosphorus concentrations range from 15 to $168 \mu \mathrm{g} \mathrm{PL}^{-1}$ and chlorophyll a concentrations are low (ranging from 2.6 to $3.9 \mu \mathrm{g} \mathrm{L}^{-1}$; Rangel et al., 2012). Water transparency is high (Secchi disk depth of 4-8 m near the dam; Rangel et al., 2012) and the bottom water is oxygenated year round, even though the water column is often stratified near the dam (V. L. M. Huszar, personal communication, 2012).

\subsection{Sampling}

Sediment cores $(6 \mathrm{~cm}$ internal diameter) were sampled at 16 sites of which 12 were located in the pelagic zone, i.e., in the area of highest sediment accumulation within transversal transects (from margin to margin), and 4 sites were located close to the margins, i.e., in the area of low sediment accumulation (Fig. 1). In one of the margin sites (site 11) the sediment was fully composed of compact pre-flooding soil, i.e., OC burial was zero. From each of the remaining 15 sites, two sediment cores were retrieved using a gravity corer equipped with a hammer device (UWITEC, Mondsee, Austria). The 
core was hammered into the sediment as deep as possible resulting in cores containing the entire sediment layer at the sampling site and preferentially pre-flooding sediment/soil as well. After retrieval, the cores were sealed with plastic caps and transported to the field station for slicing. The first set of cores was used for determination of sediment accumulation rate, OC burial (or OC accumulation) rates (Mendonça et al., 2014) and physical and chemical analysis. The second set of cores was used for measurements of $\mathrm{O}_{2}$ and $\mathrm{CH}_{4}$ concentrations in pore water depth profiles.

\subsection{Sediment characteristics}

One sediment core from each sampling site (including preflooding material, when present) was subsampled in $2 \mathrm{~cm}$ thick slices which were stored in air-tight plastic containers at $-5^{\circ} \mathrm{C}$ until further lab analysis. At the lab, water and organic matter contents (\%) of each slice were measured gravimetrically, based on the difference between wet and dry weights and loss on ignition, at $550{ }^{\circ} \mathrm{C}$ for $4 \mathrm{~h}$, respectively. Sediment porosity $(\varnothing)$ was calculated from water content (WC) and dry bulk density $(\rho)$, as follows:

$\varnothing=\mathrm{WC} /(\mathrm{WC}+(1-\mathrm{WC}) \times \rho)$.

Dry bulk density $(\rho)$ was calculated assuming that sediment is formed by a mixture of minerals (approximate density of $2.65 \mathrm{~g} \mathrm{~cm}^{-3}$ ) and organic matter (approximate density of $\left.1 \mathrm{~g} \mathrm{~cm}^{-3}\right)$ :

$\rho=\mathrm{OM} \times 1+\mathrm{IM} \times 2.65$,

where $\mathrm{OM}$ is the fraction of organic matter and IM the fraction of inorganic matter in the sediment $(\mathrm{OM}+\mathrm{IM}=1)$. $\mathrm{OC}$ content, nitrogen content and carbon isotopic composition $\left(\delta^{13} \mathrm{C}\right)$ were determined using a $\mathrm{CN}$ analyzer (ANCA-GSL, PDZ Europa, Ltd., Sandbach, UK) coupled to a mass spectrometer (Sercon Ltd., Cheshire, UK). These analyses were performed in the two top slices, in the two bottom postflooding sediment slices, in the two top pre-flooding slices, and in one slice every $10 \mathrm{~cm}$ along the entire cores (except for site 1 where we analyzed all slices). OC content in the nonanalyzed slices was estimated by linear interpolation. Particulate inorganic carbon was not present in the sediment since sediment samples did not react when exposed to acid $(\mathrm{HCl})$, in accordance with water $\mathrm{pH}$ in the Mascarenhas de Moraes reservoir varying between 6.6 and 7.8 (Rangel et al., 2012).

\subsection{Gas concentrations in pore water}

At the field station, profiles of oxygen concentration and samples for $\mathrm{CH}_{4}$ analysis were immediately acquired. Oxygen concentrations in sediment pore water were measured using a microsonde (model PA 2000, UNISENSE, Aarhus, Denmark) equipped with a microelectrode (Clark type). Calibration was performed using air-saturated and oxygen-free solutions, prepared by bubbling air (air-saturated solution) and pure nitrogen gas (oxygen-free solution) into distilled water for approximately $30 \mathrm{~min}$. Analytical precision was $0.1 \mu \mathrm{mol} \mathrm{L} \mathrm{L}^{-1}$. The microelectrode was moved vertically in steps of $1 \mathrm{~mm}$ from the sediment-water interface down to the anoxic layer. Oxygen exposure time (yr) for each core was calculated as the ratio between oxygen penetration depth $(\mathrm{cm})$ and sediment accumulation rate $\left(\mathrm{cm} \mathrm{yr}^{-1}\right)$.

Samples for the analysis of $\mathrm{CH}_{4}$ dissolved in pore water were taken after carefully transferring the sediment from the sampling tube into a tube with the same dimensions but equipped with spiral-wise positioned sampling ports of $2 \mathrm{~cm}$ diameter every $2 \mathrm{~cm}$ along the length of the tube. Approximately $10 \mathrm{~mL}$ of sediment was retrieved using a plastic syringe through each sampling port (starting from the top layers). The sediment was then transferred to glass vials which were immediately sealed with a silicon septa and an aluminum crimp seal. After taking $4 \mathrm{~mL}$ of air out though the silicon septa, using a syringe and a needle, $4 \mathrm{~mL}$ of $2.5 \%$ $\mathrm{NaOH}$ was injected into the vials in order to have all dissolved $\mathrm{CH}_{4}$ transferred to the headspace; vials were shaken and stored upside down until analysis.

Concentrations of $\mathrm{CH}_{4}$ in pore water were determined by injecting $1 \mathrm{~mL}$ of equilibrated headspace air into a gas chromatograph (Shimadzu GC-2010) equipped with a flame ionization detector (FID). Ultra pure nitrogen, hydrogen and synthetic air were used as carrier gases. Injection, detection and column temperatures were 120,200 and $85^{\circ} \mathrm{C}$, respectively. Headspace $\mathrm{CH}_{4}$ concentrations were expressed as $\mathrm{mmol} \mathrm{L}^{-1}$, in relation to a known concentration standard. From the headspace concentrations $\left(\left[\mathrm{CH}_{4}\right]_{\mathrm{h}}\right)$, pore water $\mathrm{CH}_{4}$ concentrations $\left(\left[\mathrm{CH}_{4}\right]_{\mathrm{pw}}\right)$ were determined as follows:

$\left[\mathrm{CH}_{4}\right]_{\mathrm{pw}}=\left(\left[\mathrm{CH}_{4}\right]_{\mathrm{h}} \times V_{\mathrm{h}}\right) /\left(V_{\mathrm{s}} \times \mathrm{WC}\right)$,

where $V_{\mathrm{h}}$ is the headspace volume (determined from the weight of water necessary to fill the headspace, considering water density $=1 \mathrm{~g} \mathrm{~cm}^{-3}$ ), $V_{\mathrm{s}}$ is the sediment volume (determined by subtracting the headspace and the $\mathrm{NaOH}$ volumes from the total vial volume) and WC is the water content (\%).

\subsection{Gas flux estimates}

OC mineralization $\left(\mathrm{g} \mathrm{C} \mathrm{m}^{-2} \mathrm{yr}^{-1}\right)$ was estimated as the sum of $\mathrm{CO}_{2}$ and $\mathrm{CH}_{4}$ fluxes from sediment to the water calculated using Fick's first law of diffusion. Details on the calculations are as follows.

Sediment-water fluxes of $\mathrm{CO}_{2}$ were calculated based on changes in oxygen concentrations with sediment depth, using the software PROFILE (Berg et al., 1998). The calculations considered sediment porosity and the $\mathrm{CO}_{2}$ molecular diffusion coefficient which varies as a function of temperature (Broecker and Peng, 1974). Depth-integrated oxygen consumption rates were converted to $\mathrm{CO}_{2}$ production by using the respiratory coefficient of 0.9 (Granéli, 1979). 
$\mathrm{CH}_{4}$ concentrations decreased quasi-linearly from a depth of $6-10 \mathrm{~cm}$ to the top of the sediment, likely caused by $\mathrm{CH}_{4}$ oxidation at the oxic-anoxic boundary and by diffusive loss at the sediment-water interface. Diffusive fluxes of $\mathrm{CH}_{4}$ were calculated based on this gradient, assuming that it extends across the diffusive boundary layer, and thus including $\mathrm{CH}_{4}$ oxidation (e.g., Sobek et al., 2009).

\subsection{OC burial and burial efficiency}

Sediment accumulation rates $\left(\mathrm{cm} \mathrm{yr}^{-1}\right)$ were calculated as the ratio between total accumulated sediment depth $(\mathrm{cm})$ in each sampling site and the reservoir age (54 years in 2011). OC burial rate $\left(\mathrm{g} \mathrm{C} \mathrm{m}^{-2} \mathrm{yr}^{-1}\right)$ was calculated from total $\mathrm{OC}$ mass ( $\mathrm{gC}$, i.e., the sum of $\mathrm{OC}$ mass in all postflooding sediment slices) in each sampling site, core surface area $\left(2.8 \times 10^{-3} \mathrm{~m}^{2}\right)$ and the total reservoir age (see details in Mendonça et al., 2014). OCBE (\%), defined as the percentage of the total OC reaching the sediments that is present in the sediment, was calculated as the ratio between $\mathrm{OC}$ burial rate and $\mathrm{OC}$ gross sedimentation rate $\left(\mathrm{g} \mathrm{C} \mathrm{m}^{-2} \mathrm{yr}^{-1}\right)$. The gross OC sedimentation rate was calculated as the sum of OC burial and OC mineralization, which was estimated by the sum of $\mathrm{CO}_{2}$ and $\mathrm{CH}_{4}$ diffusive fluxes.

Extrapolation of the site measurements (i.e., the data we obtained from the cores) to the whole reservoir was done following two different approaches. In the first approach, we combined the relationship between OCBE and sediment accumulation rate (this relationship is strong, see Results) with the spatially resolved estimate of reservoir sediment accumulation rate (obtained from the interpolation of seismic profiles; Mendonça et al., 2014) to calculate the mean reservoir OCBE. In the second approach, we estimated the mean OCBE for the Mascarenhas de Moraes reservoir from the spatially resolved mean OC burial rate (Mendonça et al., 2014) and the mean mineralization rates estimated from the cores.

\subsection{Data analysis}

We used the Shapiro-Wilk test to check variables' distribution for normality, and the two-tailed Spearman rank-order correlation (as some of the distributions were not normal) to assess associations between variables. Distance to the dam along the rivers-dam axis was defined as the shortest distance from each sampling site to the dam, following the river/reservoir shape; because of the many tributary rivers to the reservoir, the term "rivers-dam gradient" may be more appropriate. The three sites sampled close to the margins (3, 7 and 10) were excluded from the analysis that included the rivers-dam gradient (i.e., distance to the dam) because margin sediments were very different from pelagic sediments (see Discussion). We used one-way ANOVA to test for difference of sediment characteristics and carbon fluxes between margin and pelagic sites.

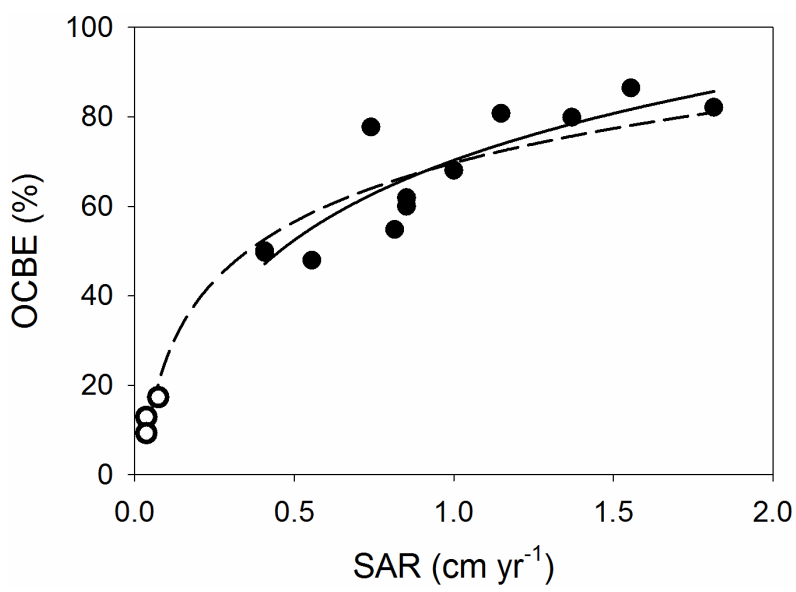

Figure 2. Relationship between OC burial efficiency (OCBE) and sediment accumulation rate (SAR) in Mascarenhas de Moraes. Open circles correspond to sites close to the margins and closed circles correspond to pelagic sites. The dashed line represents the logarithmic regression for all sites: $\mathrm{OCBE}=19.0 \ln (\mathrm{SAR})+69.7 ; R^{2}=0.92 ; p<0.0001 ; n=15$. The solid line represents the logarithmic regression for pelagic sites only: $\mathrm{OCBE}=25.8 \ln (\mathrm{SAR})+70.3 ; R^{2}=0.76 ; p<0.0001 ; n=$ 12.

\section{Results}

Sediment accumulation rates and OC burial rates at the sampling sites varied from 0.04 to $1.8 \mathrm{~cm} \mathrm{yr}^{-1}$ and from 3.1 to $210 \mathrm{~g} \mathrm{C} \mathrm{m}^{-2} \mathrm{yr}^{-1}$, respectively (Table 1 ), and significantly decreased towards the dam $(r=0.74$ and $r=0.82$, respectively; $p<0.001)$. The OC burial rates were on average 13 times higher at the pelagic sites than at the sites close to the margins (Table 1). OC mineralization rates, on the other hand, varied within a narrow range $\left(17-48 \mathrm{~g} \mathrm{C} \mathrm{m}^{-2} \mathrm{yr}^{-1}\right.$; Table 1) and did not show a specific spatial pattern. Fluxes of $\mathrm{CO}_{2}$ represented, on average, $65 \%$ of the total carbon flux from the sediment to the water in the sampling points.

Site-specific OCBE values varied from 9 to $86 \%$ (mean $56 \%$ for all sites, or $67 \%$ if only the pelagic sites were included, Table 1) and were strongly positively correlated to sediment accumulation rates (Fig. 2) but only weakly correlated to sediment composition (OC content and isotopic composition) and oxygen exposure time (Fig. 3).

The mean OC content in the sampled cores in Mascarenhas de Moraes varied from 1.2 to $3.1 \%$ for the pelagic sites and from 1.8 to $2.5 \%$ for the margin sites. Mean $\delta^{13} \mathrm{C}$ and mean $\mathrm{C}: \mathrm{N}$ ratio in the sampled cores varied from -23.3 to -19.8 and from 9.6 to 12.1 , respectively (Table A1 in the Appendix). Sediment became more OC-enriched and C13 -depleted towards the dam (pelagic sites only) and from the margins to the pelagic zone (Fig. 4). Oxygen penetration depth varied from 0.3 to $1.2 \mathrm{~cm}$ and did not vary significantly between margin and pelagic sites. Oxygen exposure time did not show a steady increase nor decrease along the 
Table 1. Sediment accumulation rate (SAR), OC burial, OC mineralization, OC gross sedimentation (OCS) and OC burial efficiency (OCBE) at each of the sampling sites in Mascarenhas de Moraes. Sites close to the margin $(\mathrm{M})$ and in the pelagic zone (P) in the same transects perpendicular to the rivers-dam transect are boldfaced. Numbering started at the dam (i.e., site 16 is furthest away from the dam; see Fig. 1).

\begin{tabular}{|c|c|c|c|c|c|c|c|}
\hline \multirow[t]{2}{*}{$\begin{array}{l}\text { Site number } \\
\text { (type) }\end{array}$} & \multirow[t]{2}{*}{$\begin{array}{r}\text { SAR } \\
\left(\mathrm{cm} \mathrm{yr}^{-1}\right)\end{array}$} & \multirow[t]{2}{*}{$\begin{array}{r}\text { OC burial } \\
\left(\mathrm{g} \mathrm{C} \mathrm{m}^{-2} \mathrm{yr}^{-1}\right)\end{array}$} & \multicolumn{3}{|c|}{$\begin{array}{l}\text { OC mineralization } \\
\qquad\left(\mathrm{g} \mathrm{C} \mathrm{m}^{-2} \mathrm{yr}^{-1}\right)\end{array}$} & \multirow[t]{2}{*}{$\begin{array}{r}\text { OCS } \\
\left(\mathrm{g} \mathrm{C} \mathrm{m}^{-2} \mathrm{yr}^{-1}\right)\end{array}$} & \multirow[t]{2}{*}{$\begin{array}{r}\mathrm{OCBE} \\
(\%)\end{array}$} \\
\hline & & & $\mathrm{CO}_{2}$ flux & $\mathrm{CH}_{4}$ flux & Total & & \\
\hline $1(\mathrm{P})$ & 0.56 & 34.4 & $30.4^{*}$ & 7.0 & 37.4 & 71.8 & 47.9 \\
\hline $2(\mathbf{P})$ & 0.81 & 56.0 & 30.4 & 15.8 & 46.2 & 102.2 & 54.8 \\
\hline 3 (M) & 0.04 & 3.1 & 4.1 & 16.9 & 21.0 & 24.1 & 12.9 \\
\hline $4(\mathrm{P})$ & 0.41 & 37.7 & 21.4 & 16.2 & 37.6 & 75.3 & 50.0 \\
\hline $5(\mathrm{P})$ & 0.41 & 31.9 & 26.7 & 5.6 & 32.3 & 64.2 & 49.7 \\
\hline $6(P)$ & 0.74 & 58.2 & 11.4 & 5.3 & 16.7 & 75.0 & 77.7 \\
\hline $7(\mathrm{M})$ & 0.04 & 3.3 & 27.2 & 4.7 & 31.9 & 35.1 & 9.3 \\
\hline $8(\mathrm{P})$ & 1.15 & 92.9 & 18.0 & 4.2 & 22.1 & 115.0 & 80.8 \\
\hline $9(\mathbf{P})$ & 0.85 & 60.3 & 31.9 & 8.3 & 40.2 & 100.5 & 60.0 \\
\hline $10(\mathrm{M})$ & 0.07 & 7.4 & 29.9 & 5.6 & 35.5 & 42.9 & 17.3 \\
\hline $11(\mathrm{P})$ & 0.00 & n.a. & n.a. & n.a. & n.a. & n.a. & n.a. \\
\hline $12(\mathrm{P})$ & 1.81 & 209.4 & 22.3 & 23.3 & 45.6 & 255.0 & 82.1 \\
\hline $13(\mathrm{P})$ & 0.85 & 69.8 & 29.9 & 13.1 & 43.0 & 112.8 & 61.9 \\
\hline $14(\mathrm{P})$ & 1.56 & 141.1 & 18.8 & 3.3 & 22.1 & 163.2 & 86.5 \\
\hline $15(\mathrm{P})$ & 1.37 & 140.2 & 22.3 & 13.0 & 35.3 & 175.5 & 79.9 \\
\hline $16(\mathrm{P})$ & 1.00 & 102.5 & 23.1 & 25.2 & 48.2 & 150.8 & 68.0 \\
\hline
\end{tabular}

* $\mathrm{CO}_{2}$ flux was not measured at site 1 ; it was considered the same as at the closest site (site 2).

rivers-dam axis, but was significantly lower in the pelagic sediments $(0.4-1.2$ years) than in the sites close to the margins (8.1-14.9 years; Table A1 in Appendix).

The first spatially resolved estimate of OCBE, based on the strong relationship between sediment accumulation rate and OCBE and on the spatially resolved mean sediment accumulation rate from a previous study (Mendonça et al., 2014), resulted in OCBE of $57 \%$ on the entire Mascarenhas de Moraes reservoir. The second estimate, based on mean mineralization rate ( $34.3 \mathrm{~g} \mathrm{C} \mathrm{m}^{-2} \mathrm{yr}^{-1}$; Table 1$)$ and the spatially resolved mean OC burial rate $\left(42.2 \mathrm{~g} \mathrm{C} \mathrm{m}^{-2} \mathrm{yr}^{-1}\right.$; Mendonça et al., 2014), resulted in a OCBE of $55 \%$ in the Mascarenhas de Moreas reservoir.

\section{Discussion}

\subsection{Organic carbon burial efficiency in reservoirs}

Sediment OC burial was higher than or similar to OC mineralization in all pelagic sites in the Mascarenhas de Moraes reservoir, leading to site-specific OC burial efficiencies varying from 48 to $86 \%$ in pelagic sites (mean $67 \%$; Table 1). These values are close to the upper end of OCBE of natural lakes. An evaluation of OCBE in lakes mostly situated at latitude $>30^{\circ} \mathrm{N}$ (with one exception at $2^{\circ} \mathrm{S}$ ) resulted in efficiencies varying from 3 to $93 \%$ (median and mean $48 \%$; Sobek et al., 2009). Due to the positive effect of temperature on OC mineralization (Gudasz et al., 2010; Cardoso et al., 2014) OCBE may be expected to be lower in subtropical and tropical lakes (Alin and Johnson, 2007). A recent assessment on arctic lakes with low OCBE (mean $22 \%$, ranging from 11 to $32 \%$ ), however, indicated that the strong effect of environmental conditions may overrule the effect of latitude on OCBE (Sobek et al., 2014). Measurements of OCBE in man-made reservoirs are scarce, and to the best of our knowledge, limited to three studies. The first is in the tropical Lake Kariba, where OCBE at a single coring site close to the dam was estimated to be $41 \%$ (Kunz et al., 2011). As our study suggests that OCBE tends to be higher at sites far from the dam, $41 \%$ is probably at the lower end of the in-reservoir variation in Lake Kariba. The second is in the temperate Lake Wohlen, where OCBE at six coring sites ranged from 83 to $94 \%$ (mean $87 \%$; Sobek et al. 2012). The third study is in eight tropical and subtropical Brazilian systems, including the Mascarenhas de Moraes reservoir, and OCBE varied roughly from 6 to $16 \%$ (Sikar et al., 2012). These low OCBE values may be related to the sampling strategy adopted: the (one to three) sites sampled in the Brazilian reservoirs were mostly located in small arms and close to the shore. Sediment accumulation is typically low in these areas as compared to the deeper areas (e.g., Mendonça et al., 2014). Additionally, the OCBE calculations are based on current silicate settling rates, whereas historical rates were likely higher (Sikar et al., 2012) which may lead to an underestimation of OCBE. The first two examples, in combination with this study, reinforce that $\mathrm{OC}$ is buried efficiently in the sediment of man-made reservoirs and points towards reservoirs as burial-prone envi- 

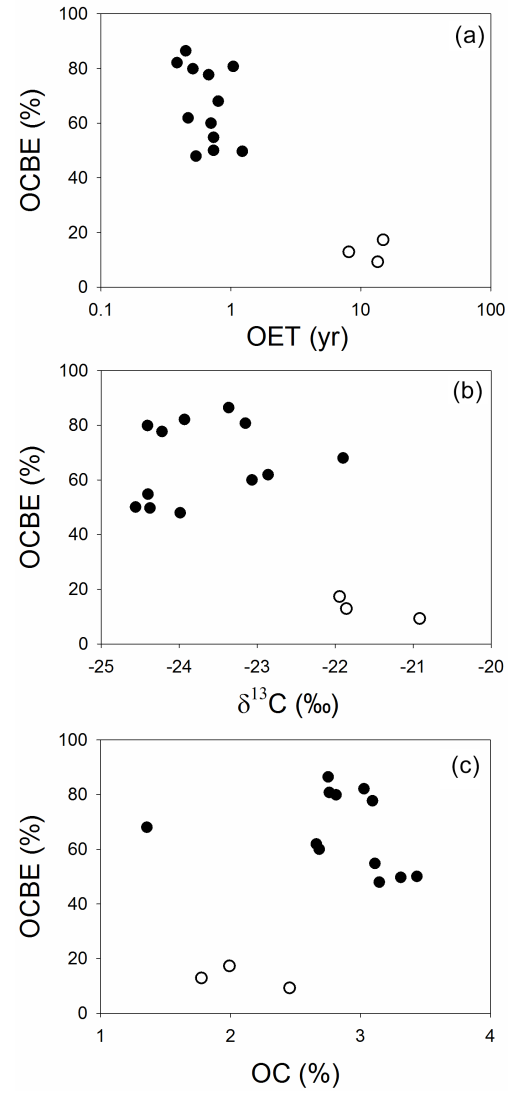

Figure 3. Relationships between OC burial efficiency (OCBE) and (a) oxygen exposure time (OET), (b) OC isotopic composition of top sediment $\left(\delta^{13} \mathrm{C}\right)$ and (c) OC content in the top sediment. In all cases, the analysis of pelagic sites alone (closed circles) resulted in non-significant correlations (Spearman; OET: $r=-0.47$, $p=0.12 ; \delta^{13} \mathrm{C}: r=-0.30, p=0.33$; OC: $r=-0.53, p=0.07$ ). If margin sites (open circles) are included, the correlation between OCBE and OET becomes significant $(r=-0.72, p=0.002)$.

ronments. In marine systems, areas with extremely high sedimentation rates, low oxygen concentrations at the bottom and a high share of terrestrially derived OC have been identified as sites of exceptionally high and efficient OC burial (Hartnett et al., 1998; Burdige, 2007; Galy et al., 2007). The fact that these characteristics are typical for many reservoirs (Dean and Gorham, 1998; Sobek et al., 2012) likely explains why OCBE in reservoirs appears to be higher than in natural lakes.

The OC mineralization in the Mascarenhas de Moraes sediments (17-48 $\mathrm{g} \mathrm{C} \mathrm{m}^{-2} \mathrm{yr}^{-1}$ ) was low when compared to other freshwater systems (e.g., 15-198 $\mathrm{g} \mathrm{C} \mathrm{m}^{-2} \mathrm{yr}^{-1}$ in temperate lakes; Sobek et al., 2009), especially due to the low $\mathrm{CO}_{2}$ fluxes. The range of $\mathrm{CO}_{2}$ fluxes $\left(4-32 \mathrm{~g} \mathrm{C} \mathrm{m}^{-2} \mathrm{yr}^{-1}\right.$ ) corresponded to the lower end in the ranges of values reported for sediments of boreal and temperate $\left(5-269 \mathrm{~g} \mathrm{C} \mathrm{m}^{-2}\right.$ $\mathrm{yr}^{-1}$, Gudasz et al., 2010) and of subtropical and tropical freshwater systems (18 to $2412 \mathrm{~g} \mathrm{C} \mathrm{m}^{-2} \mathrm{yr}^{-1}$, Cardoso et al.,

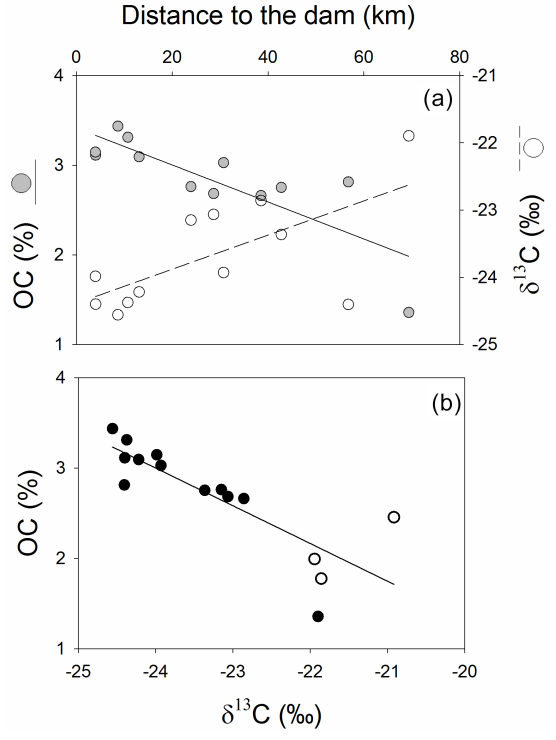

Figure 4. (a) Variation in OC content (\%) and OC isotopic composition $\left(\delta^{13} \mathrm{C}, \%\right.$ o $)$ of top sediment of pelagic sites related to the distance to the dam. The lines represent the linear trend of variation for OC (solid line, gray circles) and for $\delta^{13} \mathrm{C}$ (hashed line, white circles). Spearman correlation coefficient for OC was $r=0.81$ $(p<0.001)$ and for $\delta^{13} \mathrm{C}$ was $r=-0.53(p=0.07)$. (b) Relationship between OC content and OC isotopic composition $\left(\delta^{13} \mathrm{C}\right)$ of top sediment in all sampling sites. Open circles correspond to sites by the margins and closed circles correspond to pelagic sites. The solid line represents the linear trend of variation for all sites. Correlation between these variables was strong $(r=-0.90, p<0.0001)$.

2014). $\mathrm{CO}_{2}$ fluxes in Mascaranhas de Moraes were similar to the rates reported for three other reservoirs in the Brazilian Cerrado (mean $66 \mathrm{~g} \mathrm{C} \mathrm{m}^{-2} \mathrm{yr}^{-1}$; Cardoso et al., 2014). The range of $\mathrm{CH}_{4}$ fluxes from the Mascarenhas de Moraes sediments (3-23 $\mathrm{g} \mathrm{C} \mathrm{m}^{-2} \mathrm{yr}^{-1}$ ) was low when compared to a set of temperate lakes $\left(0.2-46 \mathrm{~g} \mathrm{C} \mathrm{m}^{-2} \mathrm{yr}^{-1}\right.$, Sobek et al., 2009). Terrestrially derived organic matter in sediments have been shown to be less labile and degrade more slowly than aquatic derived sediments (Gudasz et al., 2012), especially under low oxygen concentrations (Sobek et al., 2009). Low mineralization rates in the Mascarenhas de Moraes reservoir may, thus, result from the deposition of OC-poor (mean $2.3 \%$ OC, Table A1) and mainly terrestrially derived sediment (see Rivers-dam gradients) and from short oxygen exposure times (Table A1). However, we might have underestimated mineralization rates as we only included diffusive $\mathrm{CO}_{2}$ and $\mathrm{CH}_{4}$ fluxes from the sediment and lacked an estimate of the $\mathrm{CH}_{4}$ flux through ebullition (bubbling), which is usually an important process in tropical reservoirs (Bastviken et al., 2004). $\mathrm{CH}_{4}$ bubbling mostly occurs when the OC supply to deeper sediment layers is high (Sobek et al., 2012). In the case of the Mascarenhas de Moraes reservoir, supersaturated $\mathrm{CH}_{4}$ concentrations in sediment pore water were observed in 6 of 16 sites (example in Fig. A1). This indicates that, 
although we have no data to reliably quantify the ebullitive flux from the sites we sampled, the occurrence of ebullition is likely, especially at the six sites where $\mathrm{CH}_{4}$ supersaturation in sediment porewater was observed. A previous study in the Mascarenhas de Moraes reservoir, however, reports $\mathrm{CH}_{4}$ emission through ebullition from the water to the atmosphere to be close to zero (data from 2005 and 2006; Ometto et al., 2011). Moreover ebullition affects the sedimentary carbon budget only marginally even in reservoirs with extreme ebullition (Sobek et al., 2012). We are, therefore, confident that not including ebullition data does not affect the magnitude of our OCBE estimates for the Mascarenhas de Moraes reservoir to any large degree, especially when considering the OCBE in the whole reservoir area.

\subsection{OCBE driven by sediment accumulation rates}

According to the statistical analysis (Spearman correlation) sediment accumulation rate was the most important variable, explaining $76 \%$ (only pelagic sites; $p<0.0001 ; r=0.76$ ) and $92 \%$ (all sites; $p<0.0001 ; r=0.92$ ) of the OCBE variability (Fig. 2). Considering that OC mineralization is usually most intense in the uppermost oxygenated sediment layers (e.g., Hartnett et al., 1998), it is reasonable to conclude that rapid sedimentation directly affects OC burial (Burdige, 2007; Sobek et al., 2009). Sediment deposition creates a physical barrier to oxygen penetration, reducing the length of time sediment particles are exposed to oxygen dissolved in the pore water. Because OC mineralization is less efficient under anoxic conditions (especially so for terrestrial OC; Sobek et al., 2009), increasing sediment accumulation rates implies, then, a higher increase in OC burial than in OC mineralization.

Our statistical analysis also focused on other factors often reported to determine OCBE in aquatic systems: oxygen exposure time (Ferland et al., 2014; Sobek et al., 2009; Fenner and Freeman, 2013) and OC source (for which we used $\delta^{13} \mathrm{C}$ as a proxy; Sobek et al., 2009; Gudasz et al., 2012). Other variables potentially affecting OCBE (e.g., distance to the dam, OC content and OC mineralization rates) were included as well. Temperature, which is also clearly important (Gudasz et al., 2010; Cardoso et al., 2014) was not included in these analysis, since variation in bottom temperatures among sampling sites was small $\left(23\right.$ to $\left.25^{\circ} \mathrm{C}\right)$ and related to daily conditions (sampling was performed within 10 days) rather than to site-specific conditions.

Despite the documented effect of oxygen availability on OC mineralization, our analysis suggests a low importance of oxygen exposure time (given by the ratio between oxygen penetration depth and sediment accumulation rate) to OCBE in our data set. Probably due to the narrow range of oxygen exposure times in pelagic sites, it only explained the variability in OCBE when combining pelagic with marginal sites in one analysis (Fig. 3a). The same was observed for the effect of OC sources (see Rivers-dam gradients) and OC content on OCBE (Fig. 3b, c). It is likely that the large variability of sediment accumulation rate (with a coefficient of variation of 0.7) and its strong effect on OCBE in the Mascarenhas de Moraes reservoir outweighed the effect of other important variables.

\subsection{Rivers-dam gradients}

The usually high nutrient availability of fluvial inflow and the gradual decrease in turbulence towards the dam lead to rivers-dam gradients of, for example, sediment accumulation rates and sedimentary OC sources in reservoirs (De Junet et al., 2009). The combined effect of an increase in the relative contribution of more labile autochthonous-derived OC (further discussed below) and a decreasing sediment accumulation rate result in a decrease in OCBE towards the dam $(p=0.01 ; r=0.69)$. Thus, estimating OCBE from reservoirs based on sampling of the lacustrine zone alone and neglecting the higher sedimentation in more upstream zones may lead to significant underestimation of the total amount of buried OC.

The characterization of the OC source can be facilitated by the use of OC quality tracers (e.g., $\mathrm{C}: \mathrm{N}$ ratio and stable isotopic composition, which indicate the relative contribution of terrestrial and autochthonous OC sources; (Meyers and Ishiwatari, 1993). There was no clear trend of variation in $\mathrm{C}: \mathrm{N}$ ratios along the rivers-dam axis in the Mascarenhas de Moraes reservoir, possibly due to the narrow range of values found in the top sediment samples $(8.7-10.8)$. The $\delta^{13} \mathrm{C}$ values showed a decreasing trend, albeit only marginally significant ( $p=0.07 ; r=-0.53$ ), implying an increasing share of autochthonous OC towards the dam. The non-significant correlation was obviously caused by a single outlier - low $\delta^{13} \mathrm{C}$ $(-24.4 \%)$ indicating an atypical share of autochthonous OC in an upstream site (Fig. 4a). This is possibly caused by the occurrence of aquatic macrophytes, registered in some upstream areas of the Mascarenhas de Moraes reservoir. Furthermore, there was a strong negative correlation between the $\delta^{13} \mathrm{C}$ values and the OC content of top sediment samples (Fig. 4b), suggesting that OC increase in the Mascarenhas de Moraes sediments was indeed caused by autochthonous primary production, although the higher OC concentrations near the dam may also be due to a lower dilution with inorganic particles that have already settled near the river inlet.

In spite of the important contribution of autochthonous primary production to sediment $\mathrm{OC}$, our data suggest that terrestrial material dominates the sedimentation in the Mascarenhas de Moraes reservoir. The isotopic composition of the top sediment in all sites $(-24.6$ to $-20.0 \%$ o $)$ is similar to that of pre-flooding terrestrial material $(-23.2$ to $-19.8 \%$ ) and chlorophyll $a$ concentrations in the water are low (Rangel et al., 2012). 


\subsection{Margin-pelagic gradients}

The spatial heterogeneity in sediment accumulation rates caused OCBE to vary significantly between margin and pelagic zones in the Mascarenhas de Moraes reservoir $(p<0.0001)$. The sites close to the margins $(3,7$ and 10$)$ had the lowest sediment accumulation rates (and, thus, OC burial rates) due to the intense wind and water-current-driven, resuspension-causing sediment focusing (see Mendonça et al., 2014). Mineralization rates in these sites, though, did not differ from the pelagic area $(p=0.36)$, resulting in much lower site-specific OCBE (Table 1). Because of focusing, sediment deposited at the margins is usually considered transient storage (Blais and Kalff, 1995; Davis and Ford, 1982), and in this case, the calculated OCBE may not reflect the efficiency of long-term OC burial at those sites. It has been shown, though, that neglecting the characteristics of marginal sediment may lead to large errors on carbon flux estimations, even when integrative methods for total sediment accumulation rates (e.g., bathymetry surveys) are used (Rippey et al., 2008; Mackay et al., 2012).

The sediment in the three sites close to the Mascarenhas de Moraes margins had lower OC and organic matter contents, lower porosity and higher $\delta^{13} \mathrm{C}$ when compared to the three adjacent pelagic sites $(p<0.05$ for all variables, Table A1). Even though the marginal sites are located within the downstream half of the reservoir (Fig. 1), their sediment characteristics were only similar to those of the furthest upstream site (i.e., under higher influence of the terrestrial fluvial inputs; site 16; Table A1). This may be explained by the fact that marginal sediments receive more soil material from bank erosion, but possibly also by the fact that a higher fraction of deposited autochthonous organic matter in the marginal sediments is mineralized (probably due to higher oxygen exposure, Table A1), leading to more OC-depleted and ${ }^{13} \mathrm{C}$-enriched sediments. It suggests that even though the sediment deposits close to the margins are small and transient, marginal OC is probably highly resistant to mineralization (Gudasz et al., 2012). Indeed, mineralization rates in the margins of the Mascarenhas de Moraes reservoir were not higher than those in pelagic sites even though the marginal environment is more favorable to mineralization (e.g., higher exposure to oxygen). Thus, if marginal sediment is transported to pelagic regions (where oxygen exposure time is much smaller), it tends to be efficiently buried at those sites. Then, regardless of the final accumulation site (marginal or pelagic zone), the sediment at the margins should not be disregarded.

\subsection{Highly spatially resolved analysis of $\mathrm{OCBE}$}

Our data show that the variability in sediment accumulation rates both along the rivers-dam axes (due to gradual decrease in water sediment transport capacity) and the margin-pelagic axes (due to sediment focusing) ultimately determine the spa- tial heterogeneity of OCBE. Thus, neglecting the higher sedimentation in deltaic zones and the lower sedimentation in marginal zones may lead to significant underestimation of the fraction of $\mathrm{OC}$ buried in reservoirs. The strong predictability of OCBE based on sediment accumulation rate (Fig. 2), permits the use of spatially resolved mean sediment accumulation rate $\left(0.51 \mathrm{~cm} \mathrm{yr}^{-1}\right.$, from a seismic survey; see Mendonça et al., 2014) to estimate the spatially resolved mean OCBE in Mascarenhas de Moraes. This analysis shows that $57 \%$ of the total OC deposited into the Mascarenhas de Moraes sediments are buried while the remaining $43 \%$ are mineralized. The estimate based on the spatially resolved mean OC burial rate (Mendonça et al., 2014) and the mean mineralization rate resulted in a similar spatially resolved mean OCBE in the Mascarenhas de Moraes reservoir - 55\%. The extrapolation based on the OCBE at the pelagic sites, i.e., not applying any spatially resolved analysis, would result in an overestimation of $15-18 \%$ (mean OCBE of $67 \%$ in pelagic coring sites).

The $43 \%$ of the deposited OC that is mineralized in the Mascarenhas de Moraes sediments may contribute to the $\mathrm{CO}_{2}$ and $\mathrm{CH}_{4}$ emissions to the atmosphere. Particularly, the share emitted as $\mathrm{CH}_{4}$ represents a potential impact of dams on global warming when compared to the previous fluvial environment. Importantly, this impact cannot be estimated based on our data, which only refer to the carbon balance of the sediment, since a considerable portion of the $\mathrm{CH}_{4}$ produced in the sediment may be oxidized before reaching the atmosphere (Guerin and Abril, 2007). However, as part of the OC burial may alleviate emissions, our robust account of OCBE adds important information to the current knowledge about the net GHG emissions from hydroelectric reservoirs.

This is the first highly spatially resolved OCBE assessment that we know of. A similar approach has been used in natural boreal lakes, most of which showed mean OCBE of 5- 40\% (only one lake had OCBE of $62 \%$; Ferland et al., 2014). The high sedimentation rates in some areas of the subtropical Mascarenhas de Moraes reservoir resulted in a higher mean OCBE than in the boreal lakes, despite the negative effect of temperature on OC burial (Gudasz et al., 2010; Cardoso et al., 2014). The boreal lakes' assessment suggested that spatially resolved mean OCBE can be predicted based on lake area and shape, with small lakes acting as more efficient carbon sinks than large ones (Ferland et al., 2014). Lake models for OC burial, however, are not applicable to large reservoirs (Stallard, 1998; Clow et al., 2015) due to their distinct characteristics (for example, reservoirs have higher share of terrestrial OC but lower sediment OC concentrations and higher and more heterogeneous sedimentation rates). Therefore, the actual effect of damming rivers on the fate of terrestrial OC, which depends on the OC burial efficiency of reservoirs as compared to downstream environments, is currently largely unknown, even though our data suggest that reservoirs tend to bury OC more efficiently than natural lakes. 


\section{Appendix A}

Table A1. Water column depth (WCD) and characteristics of postflooding sediment (top $2 \mathrm{~cm}$ and mean) and oxygen exposure time in sediment (OET). Note that at site 11 sediment accumulation was zero. Sites close to the margin $(\mathrm{M})$ and in the pelagic zone $(\mathrm{P})$ in the same transects perpendicular to the rivers-dam transect are boldfaced. Numbering started at the dam (i.e., site 16 is furthest away from the dam; see Fig. 1).

\begin{tabular}{|c|c|c|c|c|c|c|c|c|c|c|}
\hline \multirow{2}{*}{$\begin{array}{l}\text { Site number } \\
\text { (type) }\end{array}$} & \multirow{2}{*}{$\begin{array}{r}\text { WCD } \\
(\mathrm{m})\end{array}$} & \multicolumn{2}{|c|}{$\mathrm{OC}(\%)$} & \multicolumn{2}{|c|}{$\delta^{13} \mathrm{C}(\% \circ)$} & \multicolumn{2}{|c|}{$\mathrm{C} / \mathrm{N}$} & \multicolumn{2}{|c|}{ Porosity $\varnothing$} & \multirow{2}{*}{$\begin{array}{r}\text { OET } \\
(\mathrm{yr})\end{array}$} \\
\hline & & $2 \mathrm{~cm}$ & Mean & $2 \mathrm{~cm}$ & Mean & $2 \mathrm{~cm}$ & Mean & $2 \mathrm{~cm}$ & Mean & \\
\hline $1(\mathrm{P})$ & 40 & 3.1 & 2.6 & -24.0 & -22.7 & 8.7 & 9.6 & 0.74 & 0.61 & 0.5 \\
\hline $2(P)$ & 38 & 3.1 & 2.7 & -24.4 & -22.4 & 9.5 & 11.2 & 0.61 & 0.48 & 0.7 \\
\hline $3(\mathrm{M})$ & 13 & 1.8 & 1.8 & -21.9 & -21.9 & 10.8 & 10.8 & 0.26 & 0.26 & 8.1 \\
\hline $4(\mathrm{P})$ & 30 & 3.4 & 2.6 & -24.6 & -21.3 & 9.7 & 9.9 & 0.80 & 0.61 & 0.7 \\
\hline $5(\mathrm{P})$ & 22 & 3.3 & 2.9 & -24.4 & -23.3 & 9.1 & 9.7 & 0.72 & 0.60 & 1.2 \\
\hline $6(P)$ & 39 & 3.1 & 3.1 & -24.2 & -21.0 & 8.9 & 11.2 & 0.77 & 0.60 & 0.7 \\
\hline $7(\mathrm{M})$ & 8 & 2.5 & 2.5 & -20.9 & -20.9 & 9.6 & 9.6 & 0.48 & 0.48 & 13.5 \\
\hline $8(\mathrm{P})$ & 26 & 2.8 & 2.1 & -23.2 & -19.8 & 9.6 & 10.9 & 0.75 & 0.48 & 1.0 \\
\hline $9(\mathbf{P})$ & 30 & 2.7 & 2.4 & -23.1 & -22.1 & 9.6 & 10.0 & 0.71 & 0.52 & 0.7 \\
\hline $10(M)$ & 10 & 2.0 & 1.9 & -21.9 & -21.7 & 9.9 & 10.6 & 0.41 & 0.36 & 14.9 \\
\hline $11(\mathrm{P})$ & 5 & & & & & & & & & \\
\hline $12(\mathrm{P})$ & 10 & 3.0 & 2.7 & -23.9 & -22.0 & 8.8 & 9.7 & 0.52 & 0.31 & 0.4 \\
\hline $13(\mathrm{P})$ & 20 & 2.7 & 2.2 & -22.9 & -20.1 & 10.1 & 12.1 & 0.68 & 0.45 & 0.5 \\
\hline $14(\mathrm{P})$ & 24 & 2.8 & 2.1 & -23.4 & -20.6 & 9.6 & 11.2 & 0.57 & 0.33 & 0.5 \\
\hline $15(\mathrm{P})$ & 10 & 2.8 & 2.1 & -24.4 & -21.8 & 9.9 & 11.8 & 0.55 & 0.28 & 0.5 \\
\hline $16(\mathrm{P})$ & 2 & 1.4 & 1.2 & -21.9 & -20.2 & 9.1 & 11.3 & 0.23 & 0.15 & 0.8 \\
\hline
\end{tabular}




\section{Appendix B}

$$
\mathrm{CH}_{4}\left(\mathrm{mg} \mathrm{L}^{-1}\right) \quad \mathrm{CH}_{4}\left(\mathrm{mg} \mathrm{L}^{-1}\right)
$$

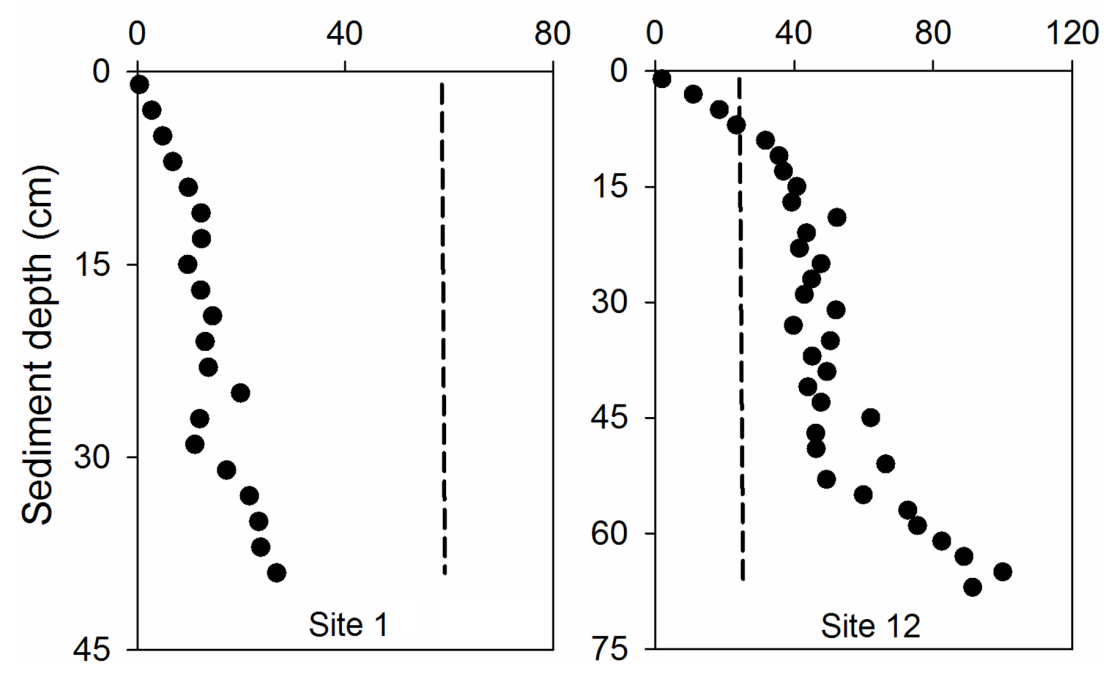

Figure B1. Example of $\mathrm{CH}_{4}$ profiles from two coring sites showing the absence (site 1) and the presence (site 12) of $\mathrm{CH}_{4}$ supersaturation in the sediment pore water. The dots represent measurements of $\mathrm{CH}_{4}$ concentration in pore water and the dashed lines represent the calculated $\mathrm{CH}_{4}$ saturation concentration. Saturation concentration (i.e., the maximum concentration that dissolves in water, above which bubbles are formed) was calculated based on pressure and temperature along the sediment profile. 
Author contributions. Raquel Mendonça, Sarian Kosten and Fábio Roland planned the manuscript and designed the sampling strategy. Raquel Mendonça, Carlos Henrique Duque Estrada, Sarian Kosten and Simone Jaqueline Cardoso did the field work. Raquel Mendonça and Marcos Paulo Figueiredo-Barros carried out laboratory analysis. Raquel Mendonça, Sebastian Sobek, Sarian Kosten and Simone Jaqueline Cardoso carried out data analysis. All authors contributed to writing the manuscript.

Acknowledgements. The authors acknowledge support from the European Research Council - ERC (Raquel Mendonça, Sebastian Sobek), Coordenação de Aperfeiçoamento de Pessoal de Nível Superior - CAPES (Raquel Mendonça, Simone Jaqueline Cardoso), NWO-Veni grant 86312012 (Sarian Kosten), and Conselho Nacional de Investigação Científica e Tecnológica CNPq (Fábio Roland). This research counted with financial support by ERC and Furnas Centrais Elétricas. Data are available on request from Raquel Mendonça.

Edited by: S. Pantoja

\section{References}

Abril, G., Guerin, F., Richard, S., Delmas, R., Galy-Lacaux, C., Gosse, P., Tremblay, A., Varfalvy, L., Dos Santos, M. A., and Matvienko, B.: Carbon dioxide and methane emissions and the carbon budget of a 10-year old tropical reservoir (Petit Saut, French Guiana), Global Biogeochem. Cy., 19, GB4007, doi:10.1029/2005GB002457, 2005.

Alin, S. and Johnson, T. C.: Carbon cycling in large lakes of the world: A synthesis of production, burial, and lake-atmosphere exchange estimates, Global Biogeochem. Cy., 21, GB300230, doi:10.1029/2006GB002881, 2007.

Armengol, K., Garcia, J. C., Comerma, M., Romero, M., Dolz, J., Roura, M., Han, B. H., Vidal, A., and Simek, K.: Longitudinal processes in canyon type reservoirs: The case of Sau (NE Spain), in: Theoretical reservoir ecology and its applications, edited by: Tundisi, J. G. and Straškraba, M., International Institute of Ecology, Brazilian Academy of Sciences and Backhuys Publishers, Leiden, 313-345, 1999.

Barros, N., Cole, J. J., Tranvik, L. J., Prairie, Y. T., Bastviken, D., Huszar, V. L. M., del Giorgio, P., and Roland, F.: Carbon emission from hydroelectric reservoirs linked to reservoir age and latitude, Nat. Geosci., 4, 593-596, 2011.

Bastviken, D., Cole, J., Pace, M., and Tranvik, L.: Methane emissions from lakes: Dependence of lake characteristics, two regional assessments, and a global estimate, Global Biogeochem. Cy., 18: GB4009, doi:10.1029/2004GB002238, 2004.

Bayne, D. R., Lawrence, J. M., and McGuire, J. A.: Primary productivity studies during early years of West Point Reservoir, Alabama-Georgia, Freshwater Biol., 13, 477-489, 1983.

Berg, P., Risgaard-Petersen, N., and Rysgaard, S.: Interpretation of measured concentration profiles in sediment pore water, Limnol. Oceanogr., 43, 1500-1510, 1998.

Betts, J. N. and Holland, H. D.: The oxygen content of ocean bottom waters, the burial efficiency of organic carbon, and the regulation of atmospheric oxygen, Palaeogeogr. Palaeocl., 97, 5-18, 1991.
Blais, J. M. and Kalff, J.: The influence of lake morphometry on sediment focusing, Limnol. Oceanogr., 40, 582-588, 1995.

Broecker, W. S. and Peng, T. H.: Gas exchange rates between air and sea, Tellus, 26, 21-35, doi:10.1111/j.2153-3490.1974.tb01948.x, 1974.

Burdige, D. J.: Preservation of organic matter in marine sediments: Controls, mechanisms, and an imbalance in sediment organic carbon budgets?, Chem. Rev., 107, 467-485, 2007.

Cardoso, S. J., Vidal, L. O., Mendonça, R. F., Tranvik, L. J., Sobek, S., and Roland, F.: Spatial variation of sediment mineralization supports differential $\mathrm{CO}_{2}$ emissions from a tropical hydroelectric reservoir, Front. Microbiol., 4, 101, doi:10.3389/fmicb.2013.00101, 2013.

Cardoso, S. J., Enrich-Prast, A., Pace, M. L., and Roland, F.: Do models of organic carbon mineralization extrapolate to warmer tropical sediments?, Limnol. Oceanogr., 59, 48-54, 2014.

Clow, D. W., Stackpoole, S. M., Verdin, K. L., Butman, D. E., Zhu, Z., Krabbenhoft, D. P., and Striegl, R. G.: Organic carbon burial in lakes and reservoirs of the conterminous United States, Environ. Sci. Technol., 49, 7614-7622, 2015.

Davis, M. B. and Ford, M. S. J.: Sediment focusing in Mirror Lake, New-Hampshire, Limnol. Oceanogr., 27, 137-150, 1982.

Dean, W. E. and Gorham, E.: Magnitude and significance of carbon burial in lakes, reservoirs, and peatlands, Geology, 26, 535-538, 1998.

De Junet, A., Abril, G., Guerin, F., Billy, I., and De Wit, R.: A multitracers analysis of sources and transfers of particulate organic matter in a tropical reservoir (Petit Saut, French Guiana), River Res. Appl., 25, 253-271, 2009.

Fenner, N. and Freeman, C.: Carbon preservation in humic lakes; a hierarchical regulatory pathway, Glob. Change Biol., 19, 775784, 2013.

Ferland, M. E., Prairie, Y. T., Teodoru, C., and Giorgio, P. A.: Linking organic carbon sedimentation, burial efficiency, and longterm accumulation in boreal lakes, J. Geophys. Res.-Biogeo. 119, 836-847, 2014.

Galy, V., France-Lanord, C., Beyssac, O., Faure, P., Kudrass, H., and Palhol, F.: Efficient organic carbon burial in the Bengal fan sustained by the Himalayan erosional system, Nature, 450, 407410, 2007.

Granéli, W.: A comparison of carbon dioxide production and oxygen uptake in sediment cores from four south Swedish lakes, Ecography, 2, 51-57, 1979.

Gudasz, C., Bastviken, D., Steger, K., Premke, K., Sobek, S., and Tranvik, L. J.: Temperature-controlled organic carbon mineralization in lake sediments, Nature, 466, 478-481, 2010.

Gudasz, C., Bastviken, D., Premke, K., Steger, K., and Tranvik, L. J.: Constrained microbial processing of allochthonous organic carbon in boreal lake sediments, Limnol. Oceanogr., 57, 163$175,2012$.

Guerin, F. and Abril, G.: Significance of pelagic aerobic methane oxidation in the methane and carbon budget of a tropical reservoir, J. Geophys. Res.-Biogeo., 112, G03006, doi:10.1029/2006jg000393, 2007.

Hartnett, H. E., Keil, R. G., Hedges, J. I., and Devol, A. H.: Influence of oxygen exposure time on organic carbon preservation in continental margin sediments, Nature, 391, 572-574, 1998.

Kunz, M. J., Anselmetti, F. S., Wuest, A., Wehrli, B., Vollenweider, A., Thuring, S., and Senn, D. B.: Sediment accumulation and 
carbon, nitrogen, and phosphorus deposition in the large tropical reservoir Lake Kariba (Zambia/Zimbabwe), J. Geophys. Res.Biogeo., 116, G03003, doi:10.1029/2010jg001538, 2011.

Mackay, E. B., Jones, I. D., Folkard, A. M., and Barker, P.: Contribution of sediment focussing to heterogeneity of organic carbon and phosphorus burial in small lakes, Freshwater Biol., 57, 290304, 2012.

Mendonça, R., Kosten, S., Sobek, S., Barros, N., Cole, J. J., Tranvik, L., and Roland, F.: Hydroelectric carbon sequestration, Nat. Geosci., 5, 838-840, 2012.

Mendonça, R., Kosten, S., Sobek, S., Cole, J., Bastos, A., Albuquerque, A., Cardoso, S., and Roland, F.: Carbon Sequestration in a Large Hydroelectric Reservoir: An Integrative Seismic Approach, Ecosystems, 17, 430-441, 2014.

Meyers, P. A. and Ishiwatari, R.: Lacustrine organic geochemistry - an overview of indicators of organic-matter sources and diagenesis in lake-sediments, Org. Geochem., 20, 867-900, 1993.

Mulholland, P. J. and Elwood, J. W.: The role of lake and reservoir sediments as sinks in the perturbed global carbon cycle, Tellus, 34, 490-499, 1982.

Ometto, J. P., Pacheco, F. S., Cimbleris, A. C. P., Stech, J. L., Lorenzzetti, J. A., Assireu, A., Santos, M. A., Matvienko, B., Rosa, L. P., Galli, C. S., Abe, D. S., Tundisi, J. G., Barros, N., Mendonça, R. F., and Roland, F.: Carbon dynamic and emissions in Brazilian hydropower reservoirs, in: Energy Resources: Development, Distribution, and Exploitation, edited by: Alcântara, E., Nova Science Publishers, New York, 155-188, 2011.

Rangel, L., Silva, L., Rosa, P., Roland, F., and Huszar, V.: Phytoplankton biomass is mainly controlled by hydrology and phosphorus concentrations in tropical hydroelectric reservoirs, Hydrobiologia, 693, 13-28, 2012.

Rippey, B., Anderson, N. J., Renberg, I., and Korsman, T.: The accuracy of methods used to estimate the whole-lake accumulation rate of organic carbon, major cations, phosphorus and heavy metals in sediment, J. Paleolimnol., 39, 83-99, 2008.
Roland, F., Vidal, L. O., Pacheco, F. S., Barros, N. O., Assireu, A., Ometto, J. P. H. B., Cimbleris, A. C. P., and Cole, J. J.: Variability of carbon dioxide flux from tropical (Cerrado) hydroelectric reservoirs, Aquat. Sci., 72, 283-293, 2010.

Sikar, E., Matvienko, B., dos Santos, M. A., Patchineelam, S., Santos, E., Silva, M., Rocha, C., Cimbleris, A., and Rosa, L. P.: Silicon as a permanent-carbon sedimentation tracer, Inland Waters, 2, 119-128, 2012.

Sobek, S., Durisch-Kaiser, E., Zurbrugg, R., Wongfun, N., Wessels, M., Pasche, N., and Wehrli, B.: Organic carbon burial efficiency in lake sediments controlled by oxygen exposure time and sediment source, Limnol. Oceanogr., 54, 2243-2254, 2009.

Sobek, S., DelSontro, T., Wongfun, N., and Wehrli, B.: Extreme organic carbon burial fuels intense methane bubbling in a temperate reservoir, Geophys. Res. Lett., 39, L0140110, doi:10.29/2011gl050144, 2012.

Sobek, S., Anderson, N. J., Bernasconi, S. M., and Del Sontro, T.: Low organic carbon burial efficiency in arctic lake sediments, J. Geophys. Res.-Biogeo., 119, 1231-1243, 2014.

Stallard, R. F.: Terrestrial sedimentation and the carbon cycle: Coupling weathering and erosion to carbon burial, Global Biogeochem. Cy., 12, 231-257, 1998.

Thornton, W. K.: Perspectives on Reservoir Limnology, in: Reservoir limnology: ecological perspectives, edited by: Thornton, K. W., Kimmel, B. L., and Payne, F. E., Jonh Wiley \& Sons, New York, 1-13, 1990.

Tremblay, A., Lambert, M., and Gagnon, L.: Do hydroelectric reservoirs emit greenhouse gases?, Environ. Manage., 33, S509S517, 2004. 